\title{
Magnetic resonance imaging findings in adnexial torsion
}

\author{
Achados da ressonância magnética na torção anexial
}

\author{
Ronald Meira Castro Trindade ${ }^{1}$, Ronaldo Hueb Baroni², Michelle Rosemberg ${ }^{3}$, Marianne Siquara de Quadros ${ }^{4}$, \\ Marcelo de Castro Jorge Racy ${ }^{5}$, Adriano Tachibana ${ }^{6}$, Marcelo Buarque de Gusmão Funari ${ }^{7}$
}

\begin{abstract}
Adnexial torsion is an unusual event, but a major cause of abdominal pain in women. It is often associated with ovarian tumor or cyst, but can occur in normal ovaries, especially in children. The twisting of adnexial structures may involve the ovary or tube, but frequently affects both. In most cases, it is unilateral, with slight predilection for the right side. In imaging findings, increased ovarian volume and adnexial masses are observed, with reduced or absent vascularization. In cases of undiagnosed or untreated complete twist, hemorrhagic necrosis may occur leading to complications; in that, peritonitis is the most frequent. Early diagnosis helps preventing irreversible damage with conservative treatment, thereby saving the ovary. Limitations in performing physical examination, possible inconclusive results in ultrasound and exposure to radiation in computed tomography makes magnetic resonance imaging a valuable tool in emergency assessment of gynecological diseases. The objective of this study was to report two confirmed cases of adnexial twist, emphasizing the contribution of magnetic resonance imaging in the diagnosis of this condition.
\end{abstract}

Keywords: Ovary/pathology; Adnexal diseases/diagnosis; Adnexa uteri/diagnosis; Magnetic resonance imaging; Torsion abnormality

\section{RESUMO}

A torção anexial é um evento incomum, porém constitui importante causa de dor abdominal em mulheres. Está frequentemente associada a tumor ou cisto ovariano, mas pode ocorrer em ovários normais, principalmente em crianças. A torção de estruturas anexiais pode envolver o ovário ou a tuba, mas geralmente acomete ambos. $\mathrm{Na}$ maioria dos casos, é unilateral, com discreta predileção pelo lado direito. Como achados de imagem, observam-se massas ovarianas e aumento do volume ovariano, com redução ou ausência de sua vascularização. Se a torção for completa e não diagnosticada ou tratada, pode ocorrer necrose hemorrágica, evoluindo com complicações, sendo a peritonite a mais frequente. 0 diagnóstico precoce ajuda a prevenir danos que são irreversíveis com tratamento conservador, poupando-se 0 ovário. A limitação do exame físico, a possibilidade de resultados inconclusivos pela ultrassonografia e a exposição à radiação pela tomografia computadorizada fazem da ressonância magnética um complemento valioso na avaliação de emergência das doenças ginecológicas. 0 objetivo deste trabalho foi relatar dois casos confirmados de torção anexial, enfatizando a contribuição da ressonância magnética no diagnóstico dessa entidade.

Descritores: Ovário/patologia; Doenças dos anexos/diagnóstico; Anexos uterinos/diagnóstico; Imagem por ressonância magnética; Anormalidade torcional

\section{INTRODUCTION}

Adnexal torsion may affect the ovary, fallopian tube or both. It is an uncommon but important cause of low abdominal pain in women, and it is difficult to make the differential diagnosis with other causes of acute abdomen ${ }^{(1)}$. It is frequently associated to cystic or solid ovarian masses $(50 \text { to } 81 \%)^{(1-4)}$ that may develop a pedicle, which is a predisposing factor for partial or complete torsion. Torsion may also affect normal ovaries, usually in children, and is usually unilateral with a slight predominance on the right side, which could be explained by the left pelvis being occupied by the colon, or by hypermobility of the cecum and distal ileum, which are on the right pelvis ${ }^{(1)}$.

This report examined two confirmed case of adnexial torsion, stressing the contribution of magnetic resonance imaging (MRI) in the diagnosis of this condition.

\footnotetext{
Study carried out at Hospital Israelita Albert Einstein - HIAE, São Paulo (SP), Brazil.

1 Graduate student in Tomography and Magnetic Resonance of the Instituto de Ensino e Pesquisa of Hospital Israelita Albert Einstein - HIAE, São Paulo, Brazil.

${ }^{2} \mathrm{PhD}$; Radiologist of Hospital Israelita Albert Einstein - HIAE, São Paulo (SP), Brazil.

${ }^{3}$ Resident of Hospital Israelita Albert Einstein - HIAE, São Paulo (SP), Brazil.

${ }^{4}$ Graduate student in Tomography and Magnetic Resonance of the Instituto de Ensino e Pesquisa of Hospital Israelita Albert Einstein - HIAE, São Paulo (SP), Brazil.

${ }^{5}$ Radiologist of Hospital Israelita Albert Einstein - HIAE, São Paulo (SP), Brazil.

${ }^{6}$ Radiologist of Hospital Israelita Albert Einstein - HIAE, São Paulo (SP), Brazil.

${ }^{7} \mathrm{PhD}$; Coordinator of the Imaging Service of Hospital Israelita Albert Einstein - HIAE, São Paulo (SP), Brazil.

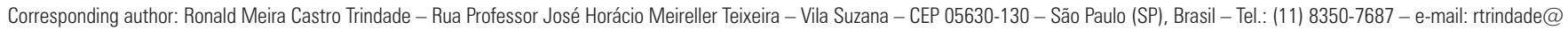
einstein.br

Received on Apr 23, 2008 - Accepted on Jul 2, 2009
} 


\section{CASE REPORTS}

\section{Case 1}

A two-year old patient with history of abdominal discomfort and low fever for one week. The initial laboratory evaluation presented leukocytosis with over 18,000 cells ( $74 \%$ segmented) and the type I urine analysis showed Gram-negative bacteriuria associated with discrete leucocyturia.

Abdominal ultrasound showed normal kidneys, bladder, uterus and right ovary. A solid-cystic nodular formation was observed in the retrovesical region, extending to the left adnexial region (Figure 1). On color Doppler, predominantly peripheral vascularization was seen around the lesion.

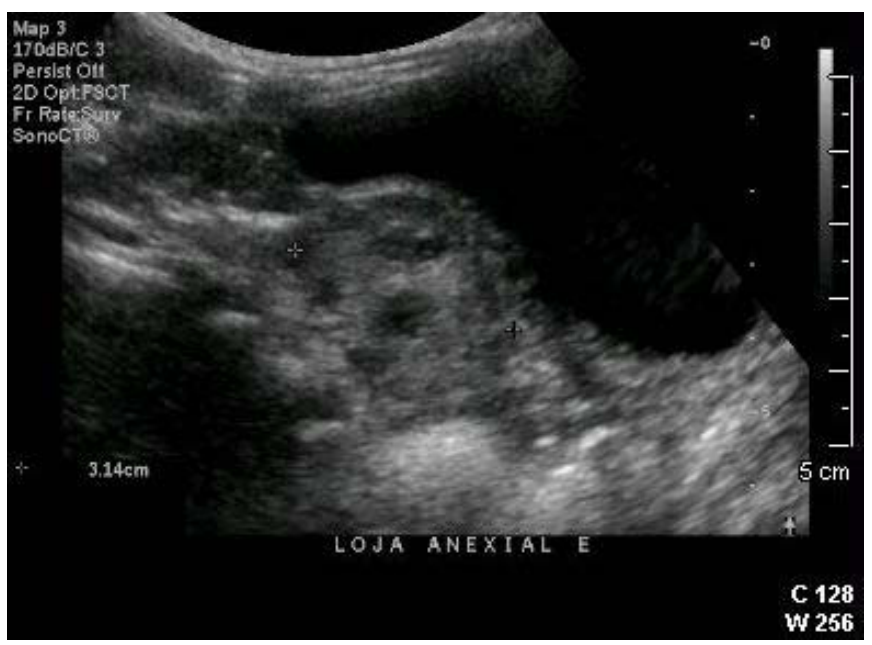

Figure 1. Ultrasonography showing a solid-cystic nodular formation occupying the retrovesical region extending to the left adnexial region

In view of the fact that the left ovary was not observed in its usual morphology, a pelvic MRI was requested in order to characterize the adnexial lesion more precisely (Figures 2, 3 and 4). It showed a large increase in volume of the left ovary and uterine tube. A

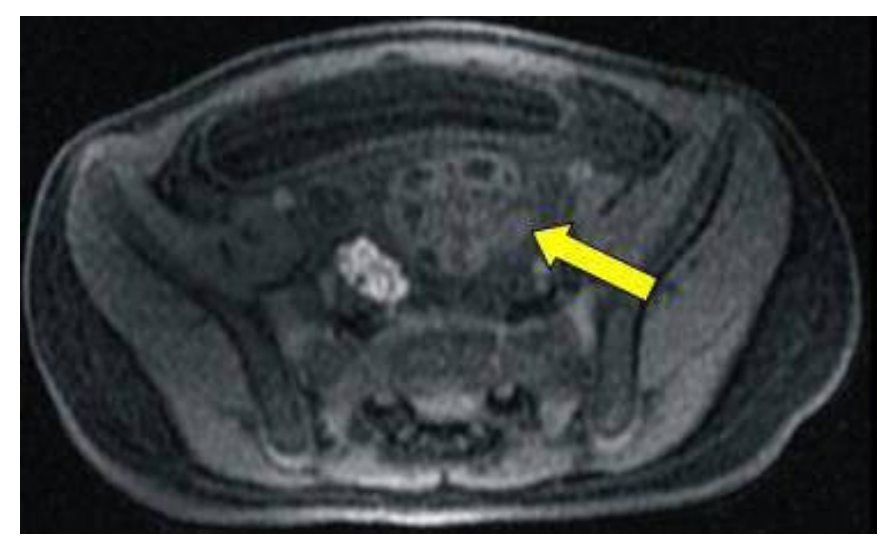

Figure 2. Axial T1 weighted MRI imaging with fat suppression, before contrast, showing enlarged left ovary, with heterogeneous sign and some high signal areas

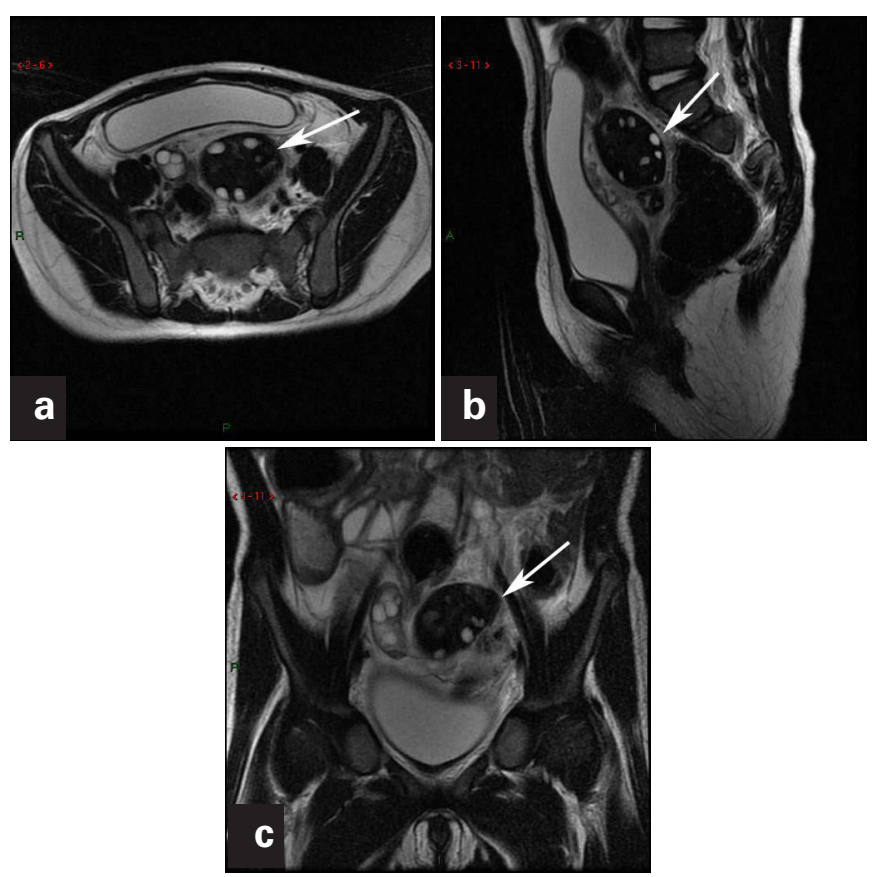

Figure 3. Weighted T2 images - (a) axial, (b) sagittal and (c) coronal - show enlarged left ovary (arrows), with predominance of low signal, and small peripheral follicles of up to $1 \mathrm{~cm}$
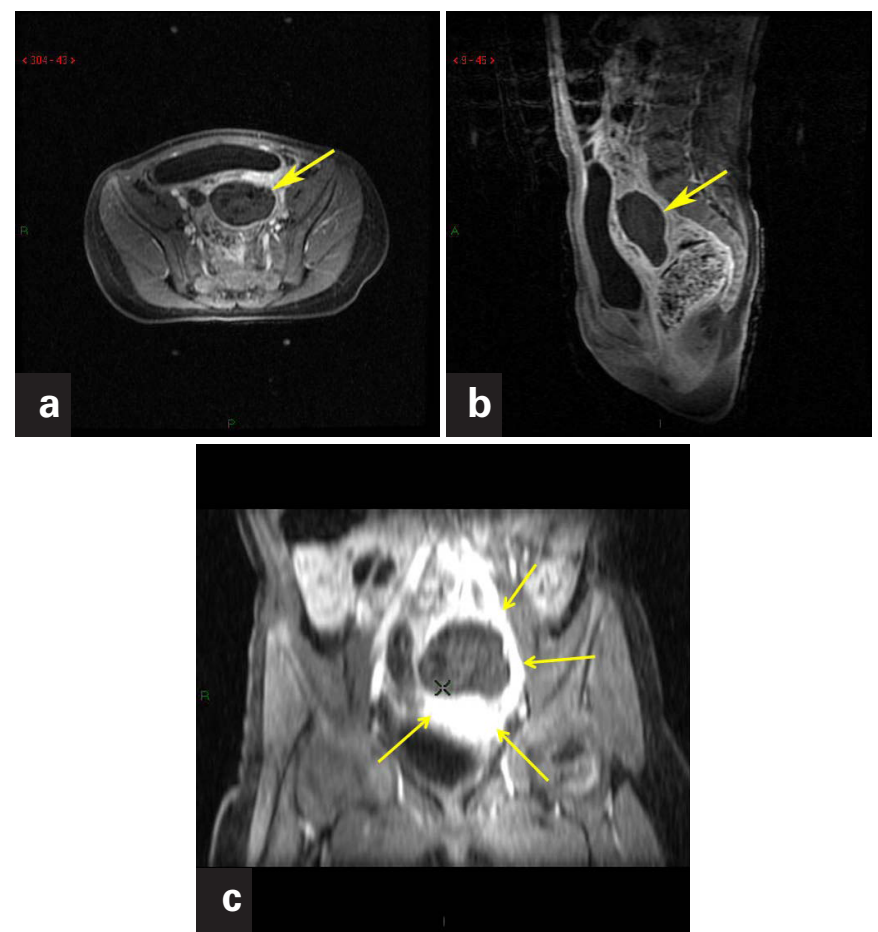

Figure 4. Weighted T1 images, after contrast with fat suppression - (a) axial, (b) sagittal and (c) coronal -, with no appropriate contrast of the left ovary. Observe intense enhancement of periovarian fat plans

heterogeneous signal of this annex was perceived with slight hypersignal areas in T1 (suggesting hemorrhage) interspersed with small cystic formations, and associated to intense alterations in signal of the periadnexial adipose planes. No enhancement of the lesion was observed in the postcontrast phases. This image corroborated the 
possibility of adnexial torsion, probably with associated hemorrhagic infarction.

Based on the MRI findings, the patient underwent surgery, characterizing left ovary/annexwith a $720^{\circ}$, torsion and a well-defined necrosis area, being submitted to a salpingo-oophorectomy. The pathological examination showed necrosis of the ovarian parenchyma and tube with extensive hemorrhagic areas thereby confirming the diagnosis of hemorrhagic infarction (Figure 5).

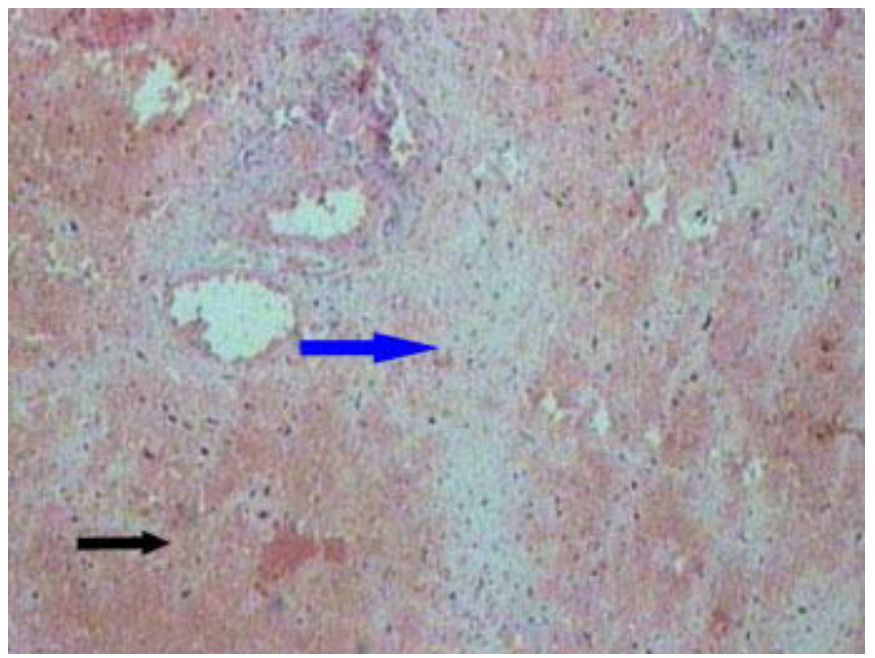

Figure 5. Histopathologic section (hematoxylin-eosin, $40 \mathrm{X}$ magnification) demonstrating extensive hemorrhage areas (black arrow) and necrosis (blue arrow)

\section{CASE 2}

A 38-year old patient with a history of low abdominal pain for one day, with nausea and vomiting (four episodes). The laboratory tests showed discreet leukocytosis, with 12,060 cells, with no shifts. The other exams were negative including type I urine analysis and $\beta$-HCG. She had been submitted to cholecystectomy and clinical diagnosis of polycystic ovary syndrome, with irregular ovarian cysts observed in a prior ultrasonography. The obstetric past history included one pregnancy and a cesarian section for twins (assisted reproduction).

A transvaginal ultrasonography was performed and showed normal uterus and right ovary (Figure 6). The left ovary presented with normal shape and
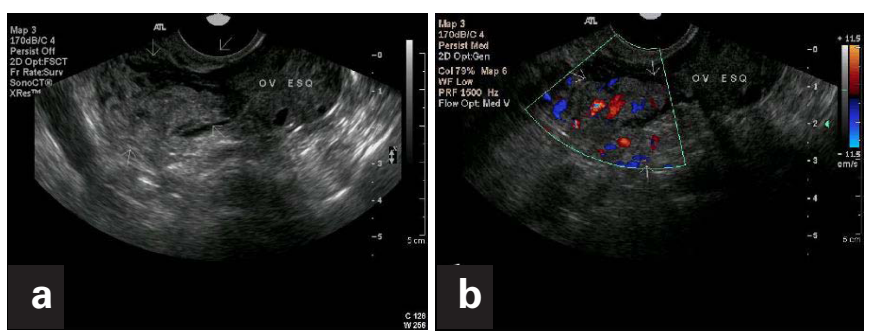

Figure 6. Transvaginal ultrasonography (a) shows the left ovary with normal shape and contour, characteristic ecotexture, with discreet increase in size, highlighting heterogenous and irregular paraovarian adnexial formation, vascularized on Doppler (b) contour, characteristic ecotexture and slightly increased dimensions. In the left adnexial region, between the uterus and ovary, a heterogeneous, irregular and unspecific formation, with vascularization, was identified. A minimal quantity of free liquid in the posterior cul de sac was seen.

In view of the findings the patient was referred to pelvic MRI, that showed a tenuous tissue with T2 low density signal posterior to the uterus, in the transition between the corpus and the cervix (Figures 7, 8, 9). The left ovary had increased volume with discreet hypersignal of the stroma in weighted T2 images, suggesting edema. There was thickening and heterogeneity in the left

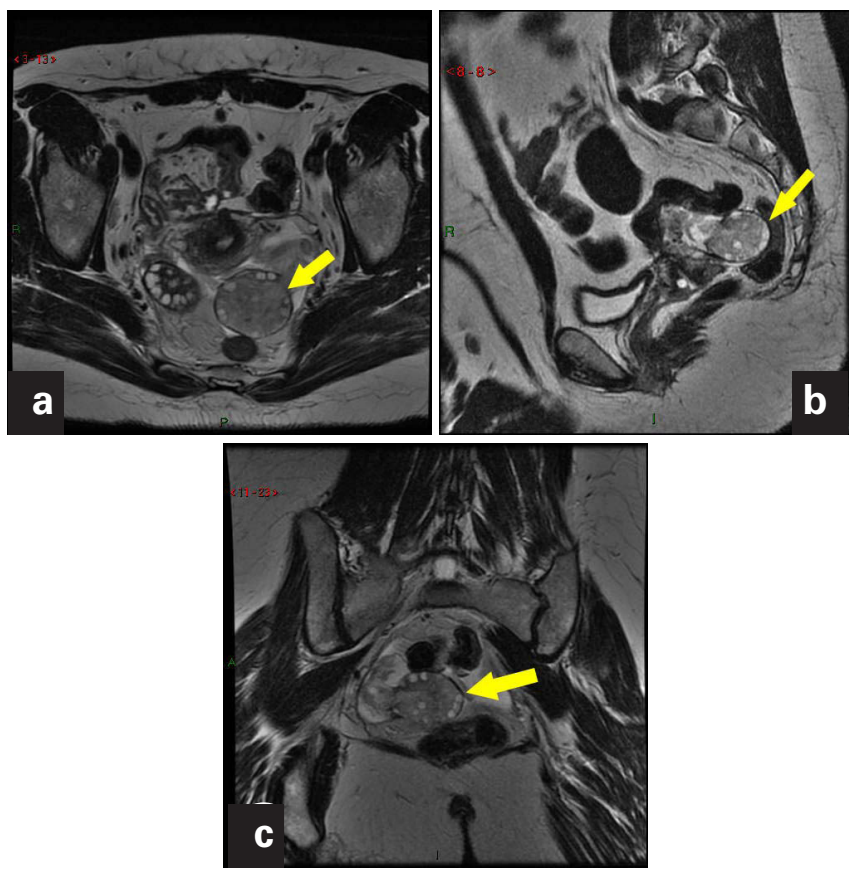

Figure 7. Weighted T2 images - (a) axial, (b) sagittal and (c) coronal - show the left ovary very enlarged, with discreet hypersignal of its stroma, suggesting edema (yellow arrows). There is thickening and mild ectasia in the left uterine tube

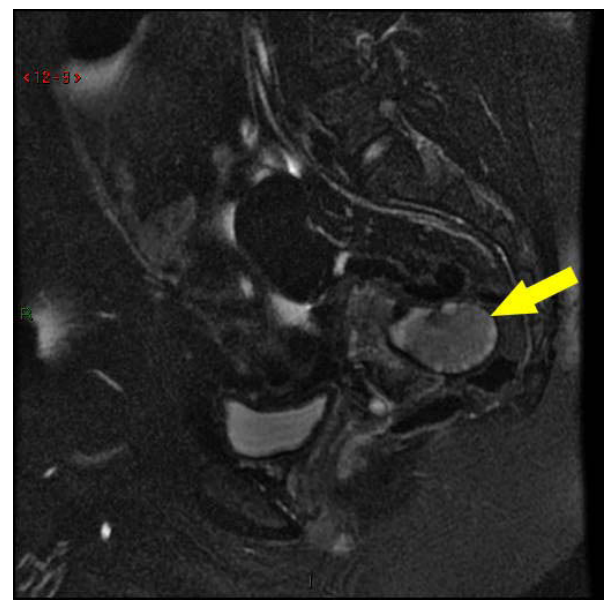

Figure 8. Weighted T2 image (sagittal) with fat suppression shows peripheral distribution of follicles and excessive ovarian stroma with high signal 


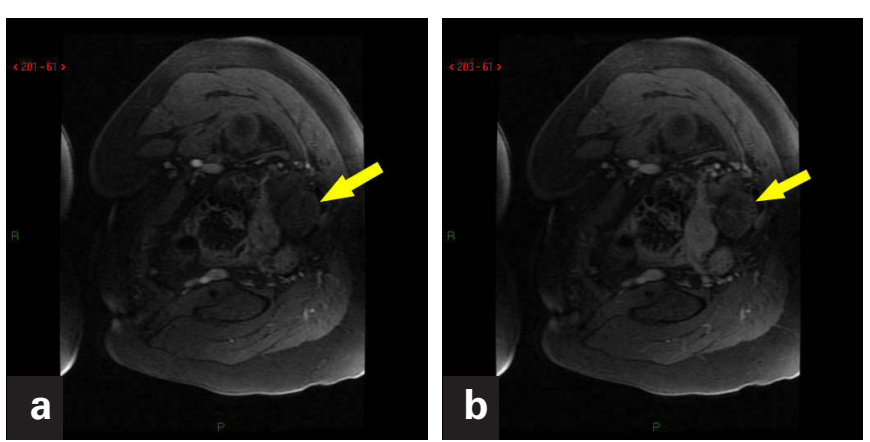

Figure 9. In weighted $\mathrm{T} 1$ images with fat suppression after early (a) and late (b) contrast there is no satisfactory contrast of the ovary and tube on the left (arrows)

uterine tube. After the venous injection of paramagnetic contrast, no satisfactory contrast of the left ovary was observed (Figure 9). The image aspect described in the resonance was compatible with the hypothesis of torsion. The patient was submitted to a videolaparoscopic surgery that showed an edematous and hyperemic left uterine tube, with enlarged ovary, with no signs of necrosis. The tubal-ovarian peritoneum showed pelvic varicose veins. A salpingectomy was performed and lysis of the ovarian-uterine adherences, with the manipulation (torsion reduction) and preservation of the left ovary. The patient involved to significant improvement of the pelvic pain and remained asymptomatic in the late postoperative stages.

\section{DISCUSSION}

The most common presentation of adnexial torsion consists in abdominal pain of sudden onset, an unspecific symptom that also appears in other clinical conditions, such as hemorrhagic acute abdomen, appendicitis and salpingitis ${ }^{(2-3)}$. Although it is considered an acute event, a subacute or intermittent course may make diagnosis more difficult ${ }^{(2)}$.

The torsion of the ovarian pedicle produces circulatory stasis that is initially venous and that evolves to an arterial component as the edema from the initial affection increases. In cases of obstruction of the arterial supply, the clinical status may also evolve to hemorrhagic-gangrenous necrosis of the ovary, and, if there is a suspicion of full torsion, immediate surgery becomes essential to remove the damaged tissue and avoid a more serious evolution to peritonitis and death $^{(1-3)}$. In both cases described, the surgical procedure was carried out as soon as the MR diagnosis was made. In the first case, a subacute history, with abdominal discomfort and low fever over a period of a week, the patient was received at the Emergency Service with no clinical signals that would suggest acute abdomen. In spite of this, magnetic resonance findings were highly suggestive of this condition, as confirmed in the surgical procedure, a $720^{\circ}$ adnexial torsion being observed, with hemorrhage areas (previously observed $\mathrm{n}$ the weighted T1 sequences) and necrosis. Therefore, it was decided to perform ooferectomy. In the second case, the more acute clinical status on onset of symptoms allows an earlier diagnosis with immediate surgical procedure through laparoscopy which enabled manual distortion and sparing the gonad.

Ultrasound is usually the first exam to be performed in emergencies, though it does not have a well-established role in early diagnosis. Its most common findings are cystic or complex solid masses, with or without fluid accumulation in the pelvis, cystic hemorrhage and parietal thickenings which were considered not specific. Doppler may be useful in the analyses of twisted structures by enabling the detection of venous and arterial flows in the vascular pedicle, but has a limited specificity as in some cases it may show normal arterial waves in the annex ${ }^{(1,5-8)}$.

The multiplanarimaging methods, such as tomography and MRI, enable a global pelvic analysis, favoring the evaluation of the uterine tube, characterization of the vascular pedicle and adnexial mass, when present, as well as detection of other peritoneal findings, such as ascites and hemoperitoneum. The rapid advance in MR techniques enabled the differential diagnosis of acute gynecological conditions, and the development of fast sequences sufficiently reduced the acquisition time for their use in emergencies ${ }^{(3)}$. One combination of weighted T1 images with and without fat suppression is useful to envisage the difference between blood and fat and improves the detection of hyperintense (hematic) lesions surrounded by fat ${ }^{(3)}$. The $\mathrm{T} 2$ weighted sequences with and without fat suppression improve conspicuousness of inflammatory lesions, besides being the ideal sequences for anatomic evaluation. The images acquired after the injection of intravenous contrast, with protocols with dynamic sequences and subtraction techniques, are useful to evaluate the lesion vascularization ${ }^{(3)}$.

Kimura et al..$^{(2)}$ demonstrated the most prevalent signs of ovarian torsion as follows: deviation of the uterus towards the torsion side, ingurgitation of the ipsilateral blood vessels, small amount of ascites and obliteration of the fatty planes around the tumor ${ }^{(1-2,7)}$, these however being unspecific signs ${ }^{(1-2)}$. The uterine deviation towards the twisting side is explained because the torsion shortens the supporting structures of the uterus. The ingurgitation of the blood vessels represents distal venous congestion to torsion and also on the surface of the tumor ${ }^{(2)}$.

Hemorrhagic necrosis due to ovarian torsion may be identified in MR examinations with a combination of T1 weighted images with the suppression of fat before and after the ministration of paramagnetic contrast, the presence of high signals in the mass was visualized (suggesting 
hemorrhage), as well as the absence of enhancement in the postgadolinium dynamic sequences ${ }^{(3)}$. Other hemorrhagic necrosis indicators include regular and excentric parietal thickening of the ovarian cystic mass, converging to a thickened tube and hematoma or twisted ovarian mass with the presence of hemoperitoneum ${ }^{(1)}$.

\section{CONCLUSION}

Magnetic resonance imaging can help diagnose the adnexial torsion, which is rare and with unspecific clinical presentation, especially in cases in which ultrasound presents negative or non-characteristic findings.

\section{ACKNOWLEDGEMENTS}

To Doctor Denise Pasqualin, pathologist at Hospital Israelita Albert Einstein (HIAE), for assistance in pathological analysis and description.

\section{REFERENCES}

1. Rha SE, Byun JY, Jung SE, Jung JI, Choi BG, Kim BS, et al. CT and MR imaging features of adnexal torsion. Radiographics. 2002;22(2):283-94.

2. Kimura I, Togashi K, Kawakami S, Takakura K, Mori T, Konishi J. Ovarian torsion: CT and MR imaging appearances. Radiology. 1994;190(2):337-41.

3. Dohke M, Watanabe Y, Okumura A, Amoh Y, Hayashi T, Yoshizako T, et al. Comprehensive MR imaging of acute gynecologic diseases. Radiographics. 2000;20(6):1551-66.

4. Outwater EK, Dunton CJ. Imaging of the ovary and adnexa: clinical issues and applications of MR imaging. Radiology. 1995;194(1):1-18

5. Bayer Al, Wiskind AK. Adnexal torsion: can the adnexa be saved? Am J Obstet Gynecol. 1994;171(6):1506-10; discussion 1510-1.

6. Lee EJ, Kwon HC, Joo HJ, Suh JH, Fleischer AC. Diagnosis of ovarian torsion with color doppler sonography: depiction of twisted vascular pedicle. J Ultrasound Med. 1998;17(2):83-9.

7. Rosado WM Jr, Trambert MA, Gosink BB, Pretorius DH. Adnexal torsion: diagnosis by using Doppler sonography. AJR Am J Roentgenol. 1992;159(6): 1251-3.

8. Nichols DH, Julian PJ. Torsion of the adnexa. Clin Obstet Gynecol. 1985;28(2): $375-80$. 